\title{
Steps for success of OCO-2
}

To the Editor - We share the excitement on the launch of OCO-2 and appreciate the editorial on the importance of observations of atmospheric carbon dioxide

(Nature Geosci. 7, 549; 2014). However, we would like to point out that OCO-2 is essentially an exploratory mission to figure out the extent to which carbon dioxide can be precisely and accurately measured from space. If OCO-2's carbon dioxide measurements improve our understanding of the carbon cycle, this will be a bonus.

From experience with the Japanese GOSAT satellite, which has been in orbit for five years, we know already that there will be significant challenges in interpreting the data, despite the fact that OCO-2 is expected to have higher performance. It is by no means a forgone conclusion that "Carbon dioxide sources and sinks can now be measured from space at high resolution".

For this to occur, the signals received by OCO-2 first need to be attributed unambiguously to variations in atmospheric $\mathrm{CO}_{2}$ concentrations (via a radiative transfer model), as opposed to variations caused, for example, by aerosols, thin clouds or other artefacts. The stringent requirement for in situ measurements is that they are free of bias to $0.1 \mathrm{ppm}$ against a global ambient level of $400 \mathrm{ppm}$. Second, even if unbiased $\mathrm{CO}_{2}$ retrievals are obtained, translating atmospheric $\mathrm{CO}_{2}$ abundance to sources and sinks requires the intermediary of an excellent model of horizontal and vertical atmospheric motion - no mean feat.

Extensive validation of both OCO-2's $\mathrm{CO}_{2}$ retrievals and atmospheric transport models will be needed before calculations of sources and sinks are credible enough to contribute in the policy arena. This will require significant investment to supplement existing networks of well-calibrated in situ $\mathrm{CO}_{2}$ measurements from surface and airborne platforms, such as NOAA’s Global Greenhouse Gas Reference Network (www.esrl.noaa.gov/gmd/ccgg/ggrn.php) or the Japanese CONTRAIL aircraft observation programme (www.cger.nies. go.jp/contrail/index.html).

OCO-2 and similar satellite missions represent ambitious and necessary experiments of how to determine carbon sources and sinks on the surface. Although the potential of satellite-based $\mathrm{CO}_{2}$ sensors is great, in the long run it will likely be a combination of remotely sensed and in situ $\mathrm{CO}_{2}$ measurements that will produce the trusted answers that society needs.

John B. Miller ${ }^{1,2 \star}$, Pieter P. Tans ${ }^{1}$ and

Manuel Gloor ${ }^{3}$

${ }^{1}$ NOAA Earth System Research Laboratory, 325 Broadway Street, Boulder, Colorado 80303, USA, ${ }^{2}$ University of Colorado, Cooperative Institute for Research in Environmental Sciences, Boulder, Colorado 80309, USA, ${ }^{3}$ University of Leeds, School of Geography, Leeds LS2 9JT, UK.

*e-mail: john.b.miller@noaa.gov

\section{Biological impact on Greenland's albedo}

To the Editor - Dumont et al. ${ }^{1}$ recently suggested that the springtime darkening of the Greenland Ice Sheet since 2009 is a consequence of an increased load of light-absorbing impurities in snow. They proposed that the impurities consist of soot or dust derived from new snow-free areas. Dumont et al. mention microorganisms as potential light-absorbing impurities, but do not incorporate biological activity into their numerical snow model. We argue that microorganisms, such as the pigmented algae that reside in snow and ice, can cause a substantial reduction in albedo and that this effect needs to be included in numerical albedo models of the Greenland Ice Sheet.

The eukaryotic algae that reside in and on snow can change the snow's colour from white to green to red over a period of weeks as the algae bloom ${ }^{2}$. Furthermore, complete melting of the snow exposes large areas of underlying grey ice that host brown-black pigmented ice-algae $e^{2-5}$, in addition to the soot and mineral dust impurities discussed by Dumont and colleagues ${ }^{1}$. The rapid colour change and the associated reduction in albedo of a Greenland glacier during the extreme 2012 summer melt season has been shown to be primarily driven by algal growth ${ }^{2}$. Green and red snow algae and brown-black ice-algae reduced snow and ice albedo, respectively, by between 30 and $40 \%$, relative to clean snow and ice ${ }^{2,3}$.

Bacteria also contribute to the darkening of ice sheets. For example, cryoconites - windblown dust particles made up of rock particles, soot and bacteria - similarly dirty Greenland's ice surface and reduce its albedo ${ }^{4,5}$.

The relative importance of biological activity versus inorganic dust and soot in the recent darkening of Greenland's snow and ice remains an open question. Dust and soot are dependent on aeolian delivery from snow- and ice-free areas, which are expanding in some regions of the Arctic as glaciers retreat. The biological contribution to albedo is, in contrast, a local, annually varying and highly dynamic feature of spring and summer melting, which could be rapidly altered by changes in the timing and duration of these seasons. We hypothesize that, as the climate warms and melt seasons become longer, biological habitats will expand and will increasingly contribute to the darkening of the Greenland Ice Sheet. Thus, we urge the inclusion of biological effects in model projections of Greenland's future albedo.

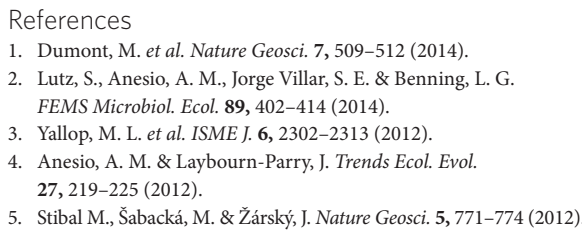

Liane G. Benning ${ }^{1 \star}$, Alexandre M. Anesio ${ }^{2}$, Stefanie Lutz $z^{1}$ and Martyn Tranter ${ }^{2}$

${ }^{1}$ Cohen Biogeochemistry Laboratory, School of Earth and Environment, University of Leeds, Leeds LS2 9JT, UK, ${ }^{2}$ Bristol Glaciology Centre, School of Geographical Sciences, University of Bristol, Bristol BS8 1SS, UK.

*e-mail: I.g.benning@leeds.ac.uk 